\title{
KELIMPAHAN DAN KEANEKARAGAMAN COLLEMBOLA PADA LIMA TIPE EKOSISTEM DI KAPUAS HULU KALIMANTAN BARAT
}

\section{ABUNDANCE AND DIVERSITY OF COLLEMBOLA IN FIVE TYPE OF ECOSYSTEM IN KAPUAS HULU WEST KALIMANTAN}

\author{
Remila Selvany $^{1}$, Rahayu Widyastuti ${ }^{1}$, Yayuk R. Suhardjono ${ }^{2}$ \\ ${ }^{1}$ Institut Pertanian Bogor, Departemen Ilmu Tanah dan Sumberdaya Lahan, Fakultas Pertanian, Jalan \\ Meranti Kampus IPB Dramaga, Bogor 16680 \\ ${ }^{2}$ Lembaga Ilmu Pengetahuan Indonesia. Peneliti Bidang Zoologi, Pusat Penelitian Biologi-LIPI. Jalan Raya \\ Jakarta-Cibinong KM. 46, Cibinong 16911 \\ E-mail: remilaselvany@gmail.com
}

(diterima Maret 2018, direvisi April 2018, disetujui Agustus 2018)

\begin{abstract}
ABSTRAK
Collembola merupakan kelompok Arthropoda yang sangat beragam dan memiliki fungsi penting di dalam ekosistem tanah. Namun, kelimpahan dan keanekaragaman Collembola di Kalimantan Barat masih sedikit dipelajari. Tujuan penelitian ini adalah untuk mendapatkan informasi kelimpahan dan keanekaragaman Collembola, serta hubungannya dengan faktor lingkungan. Sampel dikumpulkan pada Desember 2016 dan Februari 2017. Collembola dikumpulkan dari hutan alami, hutan karet, kebun kelapa sawit, ladang dan lahan marginal. Hasil penelitian diperoleh tiga ordo, 10 famili dan 26 genus dengan total 393 individu. Terdapat perbedaan pada kelimpahan dan keanekaragaman ordo, famili dan genus pada lima ekosistem yang berbeda. Perbedaan faktor lingkungan berperan penting terhadap kelimpahan dan struktur komunitas Collembola. Berdasarkan indeks keanekaragaman, hutan alami memiliki keanekaragaman Collembola tertinggi $(2,69)$, diikuti oleh hutan karet $(2,44)$, kebun kelapa sawit $(2,37)$, ladang $(1,52)$ dan lahan marginal $(0,56)$. Hasil analisis korelasi menunjukkan terdapat korelasi positif antara beberapa genus Collembola dengan $\mathrm{C}$ organik, $\mathrm{N}$ total dan $\mathrm{C} / \mathrm{N}$ rasio.
\end{abstract}

Kata kunci: Ascocyrtus, mikroarthropoda, tanah.

\begin{abstract}
Collembola is a highly diverse group of Arthropods having important function in soil ecosystem. However, Collembola diversity and abundance in West Kalimantan is poorly studied. The aim of the research was to collect the information of abundance and diversity of Collembola, and their linkages between environmental factors. Samples were collected in December 2016 and February 2017. The Collembola were collected from natural forest, rubber forest, oil palm plantation, slash and burn field and marginal land. Result showed three orders, 10 families and 26 genera with total individual 395. There are some differences in the diversity of order, family and genera in five different ecosystem. Differences of environmental factors plays an important role in influencing abundance and community structure of Collembola. Based on the Shannon's diversity index, natural forest has the highest diversity of soil Collembola (2.69), followed by rubber forest (2.44), oil palm plantation (2.37), slash and burn field (1.52) and marginal land (0.56). The result of correlation analysis showed that there were positive correlation values of some genera of Collembola with the Content of $\mathrm{C}$ organic, $\mathrm{N}$ total, and $\mathrm{C} / \mathrm{N}$ ratio.
\end{abstract}

Keywords: Ascocyrtus, microarthropods, soil.

\section{PENDAHULUAN}

Organisme tanah dengan diversitas yang tinggi, berperan dalam menjaga stabilitas ekosistem melalui interaksinya yang kompleks dalam jaring-jaring makanan (Husamah et al. 2016). Kestabilan ekosistem dapat terganggu melalui aktivitas pembukaan dan alih fungsi lahan, yang pada akhirnya berdampak pada perubahan struktur organisme tanah termasuk Collembola. Sebagai komponen ekosistem,
Collembola mempunyai peran yang beraneka ragam antara lain pengendali penyakit tanaman akibat jamur, perombak bahan organik, penyeimbang ekosistem, indikator hayati tingkat kesuburan atau keadaan tanah dan pengurai bahan beracun (Suhardjono et al. 2012). Rusek (1998) menjelaskan bahwa Collembola memegang peranan penting dalam proses dekomposisi serasah dan pembentukan mikrostruktur tanah. 
Keberadaan Collembola di dalam suatu ekosistem dipengaruhi oleh jenis ekosistem. Penyebarannya menunjukkan kemampuan adaptasi terhadap habitat dan vegetasi yang berbeda (Broza et al. 2004). Husamah et al. (2016) melaporkan bahwa keanekaragaman Collembola di hutan lebih tinggi dibandingkan di lahan pertanian dan pemukiman. Selain itu penelitian oleh Rahmadi et al. (2004), menunjukkan adanya perbedaan kelimpahan Collembola pada hutan alam dan hutan tanaman industri di kawasan hulu Sungai Tabalong, Kalimantan Selatan. Penelitian mengenai keanekaragaman Collembola telah dilakukan di berbagai wilayah di Indonesia, antara lain Sumatra telah dilakukan di Lampung (Fatimah et al. 2012), Jambi (Warino et al. 2017; Widrializa et al. 2015). Di Pulau Jawa penelitian telah dilakukan di Jawa Barat (Suhardjono 2002; Erwinda 2016), Jawa Timur (Susanti 2015). Di Pulau Sulawesi penelitian telah dilakukan di Sulawesi Tenggara (Suriana et al. 2015), di Pulau Bali dan Lombok juga telah dilakukan penelitian mengenai keanekaragaman Collembola oleh Suhardjono (1992). Di Pulau Kalimantan penelitian telah dilakukan di Kalimantan Selatan (Rahmadi et al. 2004), Kalimantan Tengah (Rahmadi \& Suhardjono 2003) dan Kalimantan Timur (Suhardjono 1985). Namun, penelitian mengenai keanekaragaman Collembola di Kalimantan Barat belum pernah dilakukan dan dilaporkan.

Terbatasnya informasi kelimpahan dan keanekaragaman Collembola pada ekosistem Kapuas Hulu menjadi pemicu untuk melakukan penelitian ini, sehingga dapat diperoleh informasi mengenai kelimpahan dan keanekaragaman Collembola. Tujuan dari penelitian ini adalah untuk mempelajari kelimpahan dan keanekaragaman Collembola di lima tipe ekosistem di Kapuas Hulu, serta pengaruh faktor lingkungan pada ekosistem yang berbeda terhadap keberadaan Collembola.

\section{METODE PENELITIAN}

\section{Waktu dan Lokasi Penelitian}

Penelitan dilakukan pada tanggal 3 sampai 12 Desember 2016 (musim hujan) dan pada tanggal 3 sampai 12 Februari 2017 (musim peralihan). Hutan alami $\left(01^{\circ} 10^{\prime} 37.61^{\prime \prime}\right.$ LU; $112^{\circ} 15^{\prime} 33.40$ 'BT) merupakan ekosistem yang memiliki indikasi jelas bahwa tidak terdapat kegiatan manusia yang berpengaruh signifikan terhadap perubahan ekologi aslinya. Hutan karet $\left(01^{\circ} 15^{\prime} 31.4^{\prime \prime}\right.$ LU; 112 $26{ }^{\prime} 31.5^{\prime \prime}$ BT) dimanfaatkan masyarakat untuk ditanami karet (Hevea sp.). Ladang (01058'15.4" LU; $111^{\circ} 53$ '11.5" BT) oleh masyarakat dibuka dengan cara tebang-bakar dan dimanfaatkan untuk penanaman padi gogo. Lahan marginal (01 ${ }^{\circ} 15^{\prime} 13.7^{\prime \prime}$ LU; $112^{\circ} 26^{\prime} 40.9$ " BT) memiliki kondisi fisik, kimia dan biologi yang rendah, tidak terdapat vegetasi berkanopi dan hanya didominasi tumbuhan pakis. Kebun kelapa sawit $\left(01^{\circ} 14^{\prime} 40.8^{\prime \prime} \quad\right.$ LU; $112^{\circ} 26^{\prime} 48.5^{\prime \prime} \quad$ BT) merupakan ekosistem yang dialihfungsikan menjadi perkebunan monokultur.

\section{Pengambilan sampel}

Pada setiap ekosistem pengamatan dibuat satu jalur transek sepanjang $100 \mathrm{~m}$ ke arah utara atau selatan mengikuti kondisi lahan. Pada garis transek ditentukan 10 titik sampling dengan jarak masing-masing $10 \mathrm{~m}$ (Suhardjono et al. 2012). Setiap titik sampling diambil sampel tanah dan serasah dengan ukuran $20 \mathrm{~cm}$ x 20 cm x 5 cm (Rahmadi et al. 2004; Suhardjono et al. 2012; Warino et al. 2017). Sampel tanah dan serasah selanjutnya diekstrak menggunakan alat 
Berlese Extractor selama lima hari (Bano \& Roy 2016). Collembola hasil ekstraksi disimpan dalam botol $50 \mathrm{ml}$ berisi alkohol $70 \%$ sebanyak $2 / 3$ volume botol. Untuk analisis $C$ organik, $\mathrm{N}$ total dan $\mathrm{C} / \mathrm{N}$ rasio, tanah diambil dari masing-masing titik kemudian dikompositkan, selanjutnya tanah dianalisis menggunakan metode CNS analyzer.

\section{Identifikasi}

Identifikasi Collembola dilakukan dengan sistem morfospesies sampai tingkat genus menggunakan kunci baku Suhardjono et al. (2012). Genus dianggap spesies karena dalam tiap genus hanya ditemukan satu spesies. Dengan demikian, morfospesies dapat mewakili spesies. Identifikasi tingkat ordo berdasarkan karakterisitik bentuk tubuh, ruas toraks, ruas perut dan oselus. Identifikasi tingkat famili berdasarkan karakteristik seta, pigmen tubuh, mandibula, furkula dan tenakulum. Identifikasi tingkat genus berdasarkan karakterisitk bentuk dan panjang ruas toraks, ukuran seta, perbandingan panjang ruas antenna I-IV, ukuran ruas abdomen kecil (ruas abdomen V-VI), dan pola warna tubuh. (Suhardjono et al. 2012).

\section{Analisis data}

Shannon diversity index (Magurran 2004) digunakan untuk mengetahui nilai keanekaragaman Collembola. Analysis of Variance (ANOVA), dilanjutkan dengan uji Duncan Multiple Range Test (DMRT) pada taraf nyata 5\% digunakan untuk melihat perbedaan populasi Collembola antar titik pengambilan sampel. Analisis korelasi Pearson digunakan untuk melihat keterkaitan unsur hara tanah terhadap jenis Collembola. Analisis statistik dilakukan dengan menggunakan perangkat lunak Statistical Product and Services Solution (SPSS) (https://spss.id.softonic.com/).

\section{HASIL DAN PEMBAHASAN}

\section{Kelimpahan dan keanekaragaman}

\section{Collembola}

Collembola yang diperoleh seluruh area yang diamati berjumlah tiga ordo, 10 famili dan 26 genus dengan total 393 individu/ sampel. Entomobryomorpha merupakan ordo dengan jumlah tertinggi mencapai 139 individu/sampel di ekosistem hutan alami. Jumlah famili yang didapatkan sekitar 52.6\% (10 famili) dari jumlah famili yang diketahui di Indonesia, yaitu 19 famili. Entomobryidae merupakan famili yang mendominasi di seluruh ekosistem dengan jumlah tertinggi mencapai 107 individu/sampel di ekosistem hutan alami. Sedangkan jumlah genus yang didapatkan sekitar $23.6 \%$ (26 genus) dari jumlah genus yang diketahui di Indonesia, yaitu 110 genus.

Collembola yang ditemukan pada ekosistem hutan alami berjumlah 172 individu/sampel dan didapatkan tiga ordo, sembilan famili, dan 20 genus. Genus Ascocyrtus memiliki jumlah tertinggi yaitu 32 individu/sampel. Jumlah genus terendah yang diperoleh yaitu Oncopodura, Harlomillsia, Tomoceridae dan Willowsia sebanyak satu individu (Tabel 1).

Collembola yang ditemukan pada ekosistem hutan karet berjumlah 119 individu/ sampel dan didapatkan dua ordo, tujuh famili, dan 19 genus. Ekosistem hutan karet didominasi oleh genus Ascocyrtus dan Coecobrya dengan masing-masing berjumlah 21 individu/sampel. Genus terendah diperoleh Lepidocyrtoides, Lepidocyrtus, Arrhopalites, 
Tabel 1. Daftar Collembola dan jumlah individu pada lima ekosistem yang berbeda.

\begin{tabular}{|c|c|c|c|c|c|c|}
\hline \multirow{2}{*}{ Ordo/Famili } & \multirow{2}{*}{ Jenis } & \multicolumn{5}{|c|}{ Ekosistem } \\
\hline & & $\mathrm{HA}$ & $\mathrm{HK}$ & $\mathrm{KS}$ & $\mathrm{L}$ & LM \\
\hline \multirow{3}{*}{$\begin{array}{l}\text { Ordo: Poduromorpha } \\
\text { Fam. Hypogstruridae }\end{array}$} & Hypogastrura sp. & 2 & 0 & 7 & 0 & 0 \\
\hline & Xenylla sp. & 0 & 0 & 1 & 0 & 0 \\
\hline & Folsomides sp. & 1 & 2 & 16 & 2 & 0 \\
\hline \multirow{7}{*}{$\begin{array}{l}\text { Ordo: Entomobryomorpha } \\
\text { Fam. Isotomidae }\end{array}$} & Folsomia sp. & 0 & 1 & 2 & 0 & 0 \\
\hline & Proisotoma sp. & 0 & 0 & 2 & 0 & 0 \\
\hline & Pseudisotoma sp. & 0 & 2 & 3 & 0 & 0 \\
\hline & Isotomiella sp. & 2 & 3 & 0 & 0 & 0 \\
\hline & Ascocyrtus sp. & 32 & 21 & 8 & 2 & 0 \\
\hline & Acrocyrtus sp. & 15 & 7 & 0 & 0 & 0 \\
\hline & Lepidocyrtoides sp. & 3 & 1 & 1 & 0 & 0 \\
\hline \multirow{6}{*}{ Fam. Entomobryidae } & Rambutsinella sp. & 14 & 8 & 1 & 5 & 0 \\
\hline & Lepidosira sp. & 18 & 5 & 2 & 0 & 4 \\
\hline & Lepidocyrtus sp. & 8 & 1 & 3 & 0 & 0 \\
\hline & Heteromurus sp. & 3 & 1 & 0 & 0 & 0 \\
\hline & Coecobrya sp. & 13 & 21 & 0 & 15 & 0 \\
\hline & Willowsia sp. & 1 & 0 & 0 & 0 & 0 \\
\hline Fam. Tomoceridae & Tomoceridae sp. & 1 & 0 & 6 & 0 & 0 \\
\hline \multirow[t]{2}{*}{ Fam. Paronellidae } & Lepidonella sp. & 10 & 11 & 0 & 0 & 2 \\
\hline & Callyntrura sp. & 15 & 0 & 1 & 0 & 0 \\
\hline \multirow[t]{2}{*}{ Fam. Oncopoduridae } & Harlomillsia sp. & 2 & 16 & 2 & 7 & 0 \\
\hline & Oncopodura sp. & 1 & 1 & 0 & 0 & 0 \\
\hline \multirow{2}{*}{$\begin{array}{l}\text { Ordo: Symphypleona } \\
\text { Fam. Arrhopalitidae }\end{array}$} & Collophora sp. & 0 & 1 & 1 & 0 & 0 \\
\hline & Arrhopalites sp. & 0 & 1 & 0 & 0 & 0 \\
\hline Fam. Sminthuridae & Sphyrotheca sp. & 9 & 13 & 8 & 2 & 0 \\
\hline Fam. Sminthurididae & Sminthurides sp. & 8 & 3 & 0 & 0 & 0 \\
\hline Fam. Dicyrtomidae & Papiroides sp. & 14 & 0 & 0 & 0 & 0 \\
\hline Total individu & & $172 d$ & $119 \mathrm{c}$ & $64 \mathrm{bc}$ & $33 \mathrm{ab}$ & $6 \mathrm{a}$ \\
\hline
\end{tabular}

Keterangan : HA (Hutan alami), HK (Hutan karet), KS (Kebun sawit), L (Ladang), LM (Lahan marginal).

Angka-angka pada baris yang sama yang diikuti oleh huruf yang sama tidak berbeda nyata pada taraf uji 5\% (uji selang berganda Duncan)

Collophora, Oncopodura, Heteromurus, dan Folsomia berjumlah satu individu/sampel (Tabel 1).

Jumlah Collembola yang diperoleh di kebun sawit lebih sedikit dari hutan alami dan hutan karet, namun lebih baik dibandingkan dengan ekosistem ladang dan lahan marginal. Hal tersebut karena adanya pemeliharaan lahan kebun kelapa sawit seperti pengaplikasian pupuk. Selain itu, lahan kelapa sawit juga memiliki daerah gawangan mati yang merupakan tempat penimbunan pangkasan pelepah sebagai sumber bahan organik.
Collembola yang ditemukan pada ekosistem kelapa sawit berjumlah 64 individu/sampel dan ditemukan tiga ordo, enam famili dan 16 genus. Genus dengan jumlah tertinggi yang diperoleh yaitu Folsomides berjumlah 16 individu/sampel, dan terendah diperoleh Xenylla, Lepidocyrtoides, Collophora, Rambutsinella dan Callyntrura berjumlah satu individu/sampel (Tabel 1).

Ekosistem ladang merupakan tipe ladang tebang bakar, sehingga mempengaruhi kondisi dan faktor lingkungan tanah. Lahan yang sudah terlalu sering dibakar 
menyebabkan hilangnya bahan organik dalam tanah, akibatnya sumber makanan sedikit, dan kondisi mikrohabitat yang tidak sesuai bagi fauna tanah termasuk Collembola. Collembola yang ditemukan pada ekosistem ladang berjumlah 33 individu dan ditemukan dua ordo, empat famili dan enam genus. Genus dengan jumlah tertinggi diperoleh Coecobrya berjumlah 15 individu/sampel, dan terendah yang ditemukan Folsomides dan Ascocyrtus berjumlah dua individu/sampel (Tabel 1).

Lahan marginal memiliki kondisi tanah yang padat, cahaya matahari langsung mengenai lantai lahan, sehingga kadar air dan kelembaban tanah rendah. Hal tersebut menyebabkan rendahnya jumlah Collembola yang ditemukan pada ekosistem lahan marginal. Collembola yang ditemukan pada ekosistem lahan marginal berjumlah enam individu/sampel dan ditemukan satu ordo, dua famili dan dua genus. Genus dengan jumlah tertinggi yang ditemukan yaitu Lepidosira berjumlah empat individu/sampel, dan terendah yang diperoleh yaitu Lepidonella berjumlah dua individu/sampel (Tabel 1).

Collembola menunjukkan kelimpahan dan keanekaragaman yang bervariasi berdasarkan tipe ekosistem (Rahmadi et al. 2003, Rahmadi et al. 2004, Fatimah et al. 2012). Secara keseluruhan, Collembola paling banyak ditemukan pada ekosistem hutan alami dan paling sedikit pada ekosistem lahan marginal (Tabel 1). Perbedaan tipe ekosistem berpengaruh terhadap keanekaragaman dan kelimpahan Collembola. Selain itu, faktor lingkungan seperti $\mathrm{pH}$ tanah, $\mathrm{C} / \mathrm{N}$ rasio dan ketersediaan sumber makanan yang berasal dari dekomposisi serasah juga ikut andil dalam mempengaruhi keanekaragaman dan kelimpahan Collembola.
Berdasarkan Uji Anova dilanjut dengan uji selang berganda Duncan, jumlah individu Collembola pada tiap ekosistem pengamatan berbeda nyata (Tabel 1). Hasil uji lanjut Duncan menyatakan bahwa jumlah individu Collembola pada ekosistem hutan alami nyata lebih tinggi dibandingkan dengan ekosistem lainnya (Tabel 1). Adanya perbedaan tersebut diduga karena perbedaan kondisi lingkungan dan nilai unsur hara di dalam tanah pada kelima ekosistem. Hal tersebut juga dibuktikan oleh Rahmadi et al. (2004) di kawasan Sungai Tabalong Kalimantan Selatan bahwa populasi Collembola tertinggi berada pada hutan alami yang memiliki kondisi serasah yang heterogen sehingga ketersediaan bahan organik sebagai sumber bahan makanan lebih tinggi dibandingkan dengan ekosistem hutan tanaman industri yang memiliki keanekaragaman vegetasi yang rendah. Sebaliknya, ekosistem lahan marginal memiliki total Collembola paling sedikit. Hal tersebut karena kondisi tanah yang padat, sumber bahan organik sedikit serta kadar air dan kelembaban tanah yang rendah sehingga kondisi tersebut tidak mendukung bagi kehidupan Collembola. Sesuai dengan Brennan et al. (2006) yang menyatakan bahwa pemadatan tanah berdampak pada terganggunya proses respirasi tanah, aktifitas mikroorganisme, dan dekomposisi bahan organik sehingga menurunkan populasi Collembola.

\section{Indeks Keanekaragaman Collembola}

Berdasarkan grafik (Gambar 1), ada perbedaan secara deskriptif terhadap keanekaragaman Collembola tanah pada ekosistem hutan alami, hutan karet, kebun kelapa sawit, ladang, dan lahan terlantar. 
Hasil penghitungan indeks keanekaragaman (H') Collembola menggunakan rumus Shannon diversity index, yaitu pada ekosistem hutan alami 2,69 (sedang), hutan karet 2,44 (sedang), kebun kelapa sawit 2,37 (sedang), ladang 1,52 (sedang), lahan marginal 0,56 (rendah).

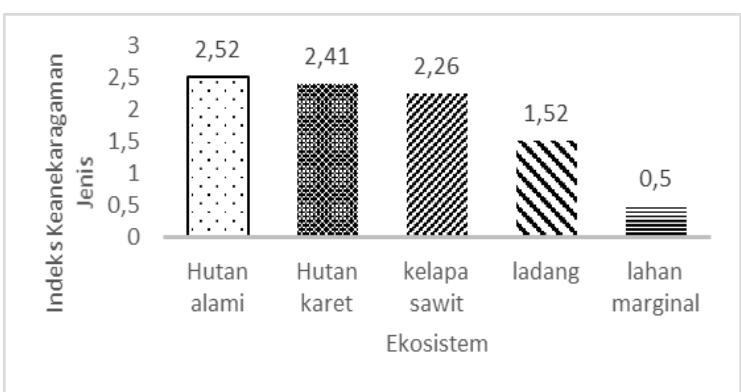

Gambar 1. indeks keanekaragaman.

Nilai Shannon's diversity index atau indeks keanekaragaman digunakan untuk membandingkan komposisi jenis dari ekosistem atau komunitas yang berbeda (Indahwati et al. 2012). Di antara lima ekosistem tersebut, hutan alami memiliki nilai indeks yang paling tinggi. Hal ini dikarenakan total Collembola yang tinggi pada ekosistem hutan alami sehingga memiliki nilai indeks yang tinggi pula. Selain itu juga diperkuat dengan data analisis unsur hara tanah yang dilakukan bahwa ekosistem hutan alami memiliki nilai $\mathrm{C}$ organik dan $\mathrm{N}$ total jauh lebih tinggi dibandingkan dengan ekosistem lain (Tabel 2).

Nilai tersebut menunjukkan bahwa ekosistem hutan alami lebih subur dan mendukung kehidupan Collembola tanah. Terkait dengan kajian kesuburan tanah, menurut Erniyani et al. (2010), tingginya nilai indeks keanekaragaman maka tingkat dekomposisi meningkat, sehingga kesuburan tanah semakin baik.

Berdasarkan nilai indeks keanekaragaman maka dapat dikatakan bahwa ekosistem hutan alami lebih stabil dibandingkan dengan ekosistem lainnya. Husamah et al. (2016) menjelaskan bahwa Keanekaragaman mempengaruhi kestabilan ekosistem, yaitu semakin tinggi keanekaragaman ekosistem, maka kondisi ekosistem tersebut cenderung stabil. Keadaan tersebut berdampak pada rantai-rantai makanan dalam ekosistem menjadi lebih panjang, lebih banyak terjadi simbiosis, dan interaksi yang lebih besar sehingga mengurangi gangguan dan meningkatkan kestabilan ekosistem.

\section{Hubungan sifat tanah dengan populasi Collembola}

Hasil analisis uji korelasi Pearson menunjukkan hubungan beberapa genus Collembola terhadap unsur hara tanah. Tinggi atau rendahnya nilai unsur hara tanah, diduga dapat mempengaruhi populasi jenis Collembola tertentu dengan nilai korelasi yang berbeda (Tabel 3, 4 dan 5).

Adanya hubungan antara genus Collembola tertentu dengan kandungan unsur

Tabel 2. Karakteristik pada lapisan tanah $(0-5 \mathrm{~cm}$ dari permukaan tanah) di lokasi penelitian.

\begin{tabular}{lcccccc}
\hline Ekosistem & $\begin{array}{c}\text { C organik } \\
(\%)\end{array}$ & N total (\%) & $\mathrm{C} / \mathrm{N}(\%)$ & $\mathrm{pH}$ & $\begin{array}{c}\text { Suhu } \\
\text { tanah } \\
\left({ }^{\circ} \mathrm{C}\right)\end{array}$ & $\begin{array}{c}\text { Kadar air } \\
(\%)\end{array}$ \\
\hline Hutan alami & 8.80 & 0.37 & 43.747 & 4 & 23 & 20.38 \\
Hutan karet & 3.71 & 0.30 & 35.759 & 4.6 & 26 & 19.66 \\
Kebun sawit & 1.26 & 0.32 & 13.227 & 4.4 & 28 & 15.47 \\
Ladang & 3.92 & 0.17 & 9.179 & 4.3 & 30 & 16.15 \\
Lahan marginal & 1.26 & 0.16 & 7.74 & 5.05 & 29 & 11.98 \\
\hline
\end{tabular}


Tabel 3. Hubungan nilai $\mathrm{C}$ organik terhadap genus Collembola tertentu.

\begin{tabular}{lc}
\hline Genus & $\begin{array}{c}\text { C organik } \\
\text { (nilai korelasi) }\end{array}$ \\
\hline Ascocyrtus (Entomobryidae) & 0.82 \\
Acrocyrtus (Entomobryidae) & 0.90 \\
Lepidocyrtoides (Entomobryidae) & 0.82 \\
Rambutsinella (Entomobryidae) & 0.96 \\
Lepidosira (Entomobryidae) & 0.85 \\
Lepidocyrtus (Entomobryidae) & 0.78 \\
Heteromurus (Entomobryidae) & 0.93 \\
Callyntrura (Paronellidae) & 0.89 \\
Oncopodura (Oncopoduridae) & 0.73 \\
Sminthurides (Sminthurididae) & 0.92 \\
Papiroides (Dicyrtomidae) & 0.90 \\
\hline
\end{tabular}

Tabel 4. Hubungan nilai $\mathrm{C} / \mathrm{N}$ rasio terhadap genus Collembola tertentu.

\begin{tabular}{lc}
\hline Genus & $\begin{array}{c}\text { C/N rasio } \\
\text { (nilai korelasi) }\end{array}$ \\
\hline Isotomiella (Isotomidae) & 0.86 \\
Ascocyrtus (Entomobryidae) & 0.94 \\
Acrocyrtus (Entomobryidae) & 0.91 \\
Lepidocyrtoides (Entomobryidae) & 0.83 \\
Rambutsinella (Entomobryidae) & 0.87 \\
Lepidosira (Entomobryidae) & 0.78 \\
Heteromurus (Entomobryidae) & 0.87 \\
Willowsia (Entomobryidae) & 0.70 \\
Lepidonella (Paronellidae) & 0.91 \\
Oncopodura (Oncopoduridae) & 0.93 \\
Sminthurides (Sminthurididae) & 0.89 \\
Papiroides (Dicyrtomidae) & 0.70 \\
\hline
\end{tabular}

Tabel 5. Hubungan nilai $\mathrm{N}$ total terhadap genus Collembola tertentu.

\begin{tabular}{lc}
\hline Genus & $\begin{array}{c}\text { t total } \\
\text { (nilai korelasi) }\end{array}$ \\
\hline Ascocyrtus (Entomobryidae) & 0.83 \\
Acrocyrtus (Entomobryidae) & 0.70 \\
Lepidocyrtoides (Entomobryidae) & 0.86 \\
Lepidocyrtus (Entomobryidae) & 0.80 \\
Sphyrotheca (Sminthuridae) & 0.81 \\
\hline
\end{tabular}

hara tanah menunjukkan bahwa kehidupan beberapa genus Collembola tersebut dipengaruhi oleh kondisi lingkungan, khususnya kandungan unsur hara tanah. Ketersediaan unsur hara tanah ini berkaitan dengan keberadaan bakteri dan fungi yang merupakan salah satu makanan bagi Collembola. Menurut Zayadi et al. (2013), faktor lingkungan seperti kelembaban tanah, $\mathrm{C} / \mathrm{N}$ dan bahan orgnik tanah mempengaruhi perbedaan struktur komunitas Arthropoda tanah, seperti Collembola. Penelitian Kaneda dan Kaneko (2004) menunjukkan bahwa peningkatan pertumbuhan Collembola sejalan dengan kenaikan nilai $\mathrm{C}$ total dan $\mathrm{N}$ total tanah. Selain itu, Agus (2007) juga 
melaporkan bahwa terdapat korelasi positif antara famili Collembola terhadap kandungan $\mathrm{C}$ organik dan $\mathrm{C} / \mathrm{N}$ rasio.

\section{KESIMPULAN}

Perbedaan kelimpahan terjadi pada lima ekosistem penelitian, diduga berkaitan dengan faktor lingkungan dan kandungan unsur hara tanah seperti $\mathrm{C}$ organik, $\mathrm{N}$ total dan $\mathrm{C} / \mathrm{N}$ rasio. Hutan alami memiliki kelimpahan dan keanekaragaman tertinggi karena memiliki nilai unsur hara yang lebih tinggi dibandingkan dengan ekosistem lainnya. Sedangkan ekosistem lahan marginal memiliki kelimpahan dan keanekaragaman yang rendah karena memiliki nilai unsur hara tanah yang paling rendah. $\mathrm{C}$ organik, $\mathrm{N}$ total dan $\mathrm{C} / \mathrm{N}$ rasio memiliki korelasi positif terhadap kelimpahan Collembola.

\section{UCAPAN TERIMA KASIH}

Penulis mengucapkan terima kasih kepada pihak Laboratorium Entomologi, Bidang Zoologi, LIPI atas bantuannya dalam proses verifikasi hasil identifikasi sampel. Penelitian ini dibiayai oleh Center for International Forestry Research (CIFOR).

\section{DAFTAR PUSTAKA}

Agus, Y. H. (2007). Keanekaragaman Collembola, Semut, dan Laba-Laba permukaan tanah pada empat tipe penggunaan lahan. Bogor: Institut Pertanian Bogor.

Bano, R. \& Roy, S. (2016). Extraction of soil microarthropoda: A low cost berlese tullgren funnels extractor. Journal of Fauna and Biological Studies, 3(2), 1417.

Broza, M., Poliakov, D., Gruia, M. \& Bretfeld,
G. (2004). Soil Collembola communities on north and south facing slopes of an eastern mediterranean valley. Pedobiologia, 48, 537-543.

Brennan, A., Fortune, T. \& Bolger, T. (2006). Collembola abundance and assemblage structure in conventionally tilled and conservation tillage arable system. Pedobiologia, 50, 135-145.

Erniyani, K., Wahyuni, S. \& Pu'u, Y. M. (2010). Struktur komunitas mesofauna tanah perombak bahan organik pada vegetasi kopi dan kakao. Agrica, 3(1), 1 -8 .

Erwinda. (2016). Keanekaragaman dan fluktuasi kelimpahan Collembola di sekitar tanaman kelapa sawit di perkebunan Cikasungka, Kabupaten Bogor. Jurnal Entomologi Indonesia, 13 (2), 99-106.

Fatimah, Cholik, E. \& Suhardjono, Y. R. (2012). Collembola permukaan tanah kebun karet, Lampung. Zoo Indonesia, 21(2), 17-22.

Husamah, Rohman, F. \& Sutomo, H. (2016). Struktur komunitas Collembola pada tiga tipe habitat sepanjang daerah aliran sungai Brantas Hulu Kota Batu. Bioedukasi, 9(1), 45-50.

Indahwati, R., Hendarto, B. \& Izzati, M. (2012, September). Keanekaragaman Arthropoda tanah di lahan apel Desa Tulungrejo Kecamatan Bumiaji Kota Batu. Makalah Seminar Nasional Pengelolaan SDA dan Lingkungan, UNDIP, Semarang.

Kaneda, S. \& Kaneko, N. (2004). Growth of the Collembola Folsomia Candida Willem in soil supplemented with glucose. Pedobiologia, 48, 165-170. 
Magurran, A. E. (2004). Measuring biological diversity. United Kingdom: Blackwell.

Rahmadi, C. \& Suhardjono, Y. R. (2003). Keanekaragaman Arthropoda tanah di lantai hutan kawasan hulu Sungai Katingan Kalimantan Tengah. Berita Biologi, 6(4), 549-554.

Rahmadi, C., Suhardjono, Y. R. \& Andayani, I. (2004). Collembola lantai hutan kawasan Sungai Tabalong Kalimantan Selatan. Biota, 9(3), 179-185.

Rusek, J. (1998). Biodiversity of Collembola and their functional role in the ecosystem. Biodiversity and conservation, 7, 1207-1219.

Suhardjono, Y. R. (1985). Perbandingan populasi serangga permukaan lantai hutan wanariset, Kalimantan Timur. Berita Biologi, 3(3), 104-106.

Suhardjono, Y. R. (1992). Fauna Collembola tanah di Pulau Bali dan Pulau Lombok. Depok: Universitas Indonesia.

Suhardjono, Y. R. (2002). Keanekaragaman fauna tanah di Cikaniki, Taman Nasional Gunung Halimun. Research and Conservation of Biodiversity in Indonesia, 9, 34-43.

Suhardjono, Y. R., Deharveng, L. \& Bedos, A. (2012). Biologi- Ekologi- Klasifikasi Collembola (EkorPegas). Bogor:
Vegamedia.

Suriana, Amirullah \& Wahyuni. (2015). Kelimpahan Collembola permukaan tanah di daerah perkebunan masyarakat di Desa Lalowiu Kecamatan Konda Kabupaten Konawe Selatan Provinsi Sulawesi Tenggara. BioWallaceae, 2(2), 7-12.

Susanti, S. F. (2015). Keanekaragaman dan kelimpahan Collembola tanah pada lahan kapur PT Semen Indonesia Tbk. di Tuban, Jawa Timur. Bogor: Institut Pertanian Bogor.

Warino, J., Widyastuti, R., Suhardjono, Y. R. \& Nugroho, B. (2017). Keanekaragaman dan kelimpahan Collembola pada perkebunan kelapa sawit di Kecamatan Bajubang, Jambi. Jurnal Entomologi Indonesia. 14(2):5157.

Widrializa, Widyastuti, R., Santosa, D. A. \& Djajakirana, G. (2015). The diversity abudance of springtail (Collembola) on forest and smallholder in Jambi. Journal of Tropical Soil, 2(3):173-180.

Zayadi, H., Hakim, L. \& Leksono, A. S. (2013). Composition and diversity of soil Arthropods of Rajegwesi Meru Betiri National Park. Journal of Tropical Life Science, 3, 166-171. 